\title{
Administering Successful Conferences in Health Education
}

\author{
Carl Hanson, M. Lelinneth, L. B. Novilla, \& Michael Barnes \\ Brigham Young University
}

\begin{abstract}
Administering conferences remains a common health education strategy especially for those functioning in leadership and administrative positions. To date, very little has been written about these events which have the potential to impact large intended audiences when successfully implemented. This paper addresses several important administrative practices that can help ensure a successful conference. These practices include but are not limited to using a health education planning model, organizing and holding committee planning meetings, preparing a budget, visiting potential conference sites, negotiating contracts for hotel and meeting facilities, corresponding with conference participants, and preparing conference materials.
\end{abstract}

(C) 2007 Californian Journal of Health Promotion. All rights reserved.

Keywords: Conference administration, conference planning, health education

Whether at the local, state, or national level, through professional associations, schools or health departments, a common administrative function of health educators in leadership positions is planning and coordinating conferences in health education. The Centers for Disease Control and Prevention (CDC) state that "A conference is a symposium, seminar, workshop, or any other organized and formal meeting lasting portions of one or more days, where persons assemble to exchange information and views or explore or clarify a defined subject, problem, or area of knowledge, whether or not a published report results from such meeting" (CDC, 1997, p. 2).

As such, conferences are useful to those in health education leadership positions who have a responsibility to facilitate professional development for training and continuing education needs. For example, the state director of health promotion might be interested in hosting a conference on best practice chronic disease prevention strategies for public health professionals while the local health educator might be concerned with training local bar tenders in a server intervention program. Conferences may also provide one way to unite professionals to participate in a common program. For example a broad group of community professionals, organizations, and community members might be united to learn more about methamphetamine abuse in their area and how to best address the problem. In addition, conferences provide a way for health educators to come together and earn continuing education credits to maintain certification as a Certified Health Education Specialist (CHES). Whatever the focus, conferences remain a common health education tool used by those in administrative and leadership positions to unite, organize, educate and train. Very little has been written in the health education literature about this important strategy.

Successful conferences require a great deal of administrative skill, time and planning. The magnitude of time and effort however is dependent on the size of the conference to be planned (US Department of Justice, 2004). Despite the size, it is helpful to treat conference planning similar to planning other health education interventions. That is, conference planning should involve: (1) establishing a planning group, (2) establishing a clear purpose, (3) identifying the intended audience, (4) understanding the needs of the intended audience, (5) planning, (6) implementation, and (7) evaluation. This model is not unfamiliar to 
health educators and can serve as a useful guide for conference planning.

Establishment of a planning committee requires representation from a number of individuals including those from the intended audience. This will help ensure that the needs of the intended audience are addressed and that one individual is not responsible for all the work. Larger conferences will require more members to assist in the decision making process to carry out responsibilities. When selecting committee members, it is helpful to select individuals who are dependable, team players, and willing to fulfill responsibilities agreed upon by the group.

A conference coordinator should be identified and often comes from within the sponsoring organization. The coordinator may be selected by the planning committee or appointed by the sponsoring organization. Either way, the responsibilities of the coordinator are important and involve both management and administrative functions which include but are not limited to: (1) organizing and holding committee planning meetings, (2) preparing a budget, (3) visiting potential conference sites, (4) negotiating contracts for hotel and meeting facilities, (5) corresponding with conference participants, and (6) preparing conference materials such as program and name badges.

As with other planning efforts, the conference coordinator should work at the outset with the planning group to review the purpose of the conference. If no purpose exists, it becomes important that the coordinator works with the planning committee to establish a clear purpose that will guide all conference activities. For example, for over 20 years the purpose of AAHPERD's College and University Administrator Council (CUAC) conference was to provide university administrators in health, physical education, recreation and dance with a forum to discuss current issues in the field and provide opportunities for networking. In this case, the planning committee also had representation from the intended audience (chairs and deans of HPERD programs) that helped to communicate their unique administrative needs. These needs led to the establishment of a conference theme that guided the development of the call for abstracts as well as the selections of speakers.

Other administrative functions that should be addressed by the coordinator and planning committee include selecting conference dates, times, locations, and facilities. Accomplishing these tasks require upfront work by the coordinator. It is important to ensure that dates are selected that do not conflict with other conferences, holidays, or events of interest to the intended audience. The coordinator should also look for the attendance incentives. For example, continuing education, networking, resource gathering through exhibitors, employment/ recruiting are typical participant needs. In addition to identifying participant's needs, also identify how the sponsoring organization can benefit from the conference. For example, getting increased local, state, regional or national exposure and enhancing collaboration, training or recruitment efforts should be considered to help guide the conference planning work.

The coordinator should also visit several potential locations and facilities to determine which might work best for achieving the conference purpose and addressing the needs of the intended audience. Many hotels and resorts will provide conference coordinators a room during site visits in order to provide an opportunity for a thorough evaluation of the facilities. These site visits not only provide opportunities to scout hotel locations and accommodations but also transportations services, restaurants and other local attractions. Resort properties and cruise ships may have excellent facilities and accommodations for conferences but should only be considered in the context of the sponsoring organization. For example, some academic institutions may not support sending faculty to a conference on a cruise ship as such a location appears to be more for entertainment than productive meeting and training.

Critical to the long term success and sustainability of conferences is the careful preparation of the budget. This administrative 
function should not be taken lightly and should include attention to all the costs associated with implementing the conference. Costs may include such items as publicity (brochures, printing, and mailing), facilities (room and equipment rentals), staff (wages), transportation (vehicle rental), meals (drinks, snacks, and meals), and conference materials (packets, name tags, etc.) (Gilgen, 2006). As wisely observed by one coordinator, "you can always do things cheaper if you don't count all the costs...so count them"(Gilgen, 2006)! One possible challenge in completing a conference budget is establishing the conference registration fee. This fee must be based on a projection of conference attendance and the associated conference costs. Keeping the registration fee realistic for the intended audience is important to ensure participation but it is also important to cover all conference costs. To help offset registration costs, conference coordinators might seek support from one or more sponsoring organizations. To get started, a downloadable budget template is provided in Table 1.

Numerous event planning software packages are also available that can provide tools for developing and tracking budgets as well as providing a way to manage registration; correspondence to participants; travel and lodging; presenters; and exhibiters. For example, OpenConf ${ }^{\circledR}$ is a free online conference management system that facilitates the electronic submission, review, and acceptance of conference papers. Thriva ${ }^{\circledR}$ on the other hand is online registration and event management software that provides event registration; registrant database, finances, and communications; credit car processing; website design and hosting; and online customer accounts. Conference coordinators interested in software tools can search online for "event planning software" to explore a wide range of options.

Sponsorships can help offset some of the costs normally incurred by a conference. Coordinators can work with the conference planning committee to identify a list of possible sponsors by asking what business, organizations or individuals would be supportive of the conference purposes. These individuals could then be approached regarding their willingness to provide financial support for such things as key note speakers, break out sessions, meals/snacks, and socials. For the CUAC Conference, Deans of HPERD colleges who saw the conference as important continuing education for their department chairs would often sponsor meals Beyond the sponsorships, another popular method of generating revenue is to charge vendors to exhibit at the conference. Fees for exhibitors would need to be developed based on the cost for exhibit space and other equipment such as tables.

Negotiating an agreement for meeting rooms and hotel accommodations is not just for larger conferences. Establishing an agreement or contract with the meeting facility despite the size of the event can provide important information about costs for budget development. These agreements normally follow several conversations between the conference coordinator or other sponsoring organization representative and the hotel or conference center manager and are traditionally affirmed in writing. Elements of an agreement that includes sleeping arrangements may also include at the least guest room commitments (number and type of rooms reserved), room rates, billing and credit arrangements, meeting room rates, exhibit space, and food and beverages (US Department of Justice, 2004).

Following the budget preparation, the work of communicating with potential attendees begins. Health educators can use their best health communication skills to design a strategy for marketing the event. While electronic means of communication (e.g., listservs and websites) are cheap, they should not the primary mode of marketing a conference. Well designed hard copy flyers and brochures continue to be the most effective tools for marketing a conference.

Administrating successful health education conferences requires attention to many important details including: registration options - preregistration, late registration; applying for CEU and CMU; conference partners/cosponsors; coordination of peer-review presentations - call 
for abstracts, abstract review; and determining appropriate types of conference sessions plenary, concurrent, and other types of sessions. These details when carefully considered throughout the planning process can help to ensure a successful event. Several online resources are available and can provide additional guidance for conference planning (see Table 1). In addition, Goldman and Schmalz (2005) have provided a comprehensive list of bulleted planning steps of pre-conference and post-conference activities.

Table 1

Conference Planning Resources

\begin{tabular}{|l|l|l|}
\hline \multicolumn{1}{|c|}{ Author } & \multicolumn{1}{c|}{ Title } & \multicolumn{1}{c|}{ URL } \\
\hline US Department of Justice & $\begin{array}{l}\text { Conference Planning } \\
\text { Guide }\end{array}$ & $\begin{array}{l}\text { http://www.ojp.usdoj.gov/ovc/publications/infores/res/c } \\
\text { onfguid/welcome.html }\end{array}$ \\
\hline Trent University & $\begin{array}{l}\text { Conference Planning } \\
\text { Guide }\end{array}$ & $\begin{array}{l}\text { http://www.trentu.ca/conferences/pdfs/TrentUniversityC } \\
\text { onferencePlanningGuide2005_000.pdf }\end{array}$ \\
\hline $\begin{array}{l}\text { The International } \\
\text { Association of Language } \\
\text { Learning Technology }\end{array}$ & $\begin{array}{l}\text { Conference Planning } \\
\text { Guidelines }\end{array}$ & $\underline{\text { http://iallt.org/confplan.html }}$ \\
\hline Conference Manager & $\begin{array}{l}\text { Conference Budget } \\
\text { Template }\end{array}$ & $\underline{\underline{\text { http://www.confmanager.com/communities/c1/files/hid }}}$ \\
\hline \begin{tabular}{l} 
den/my_conference_budget.xls \\
\hline
\end{tabular}
\end{tabular}

Planning and executing well-thought out meetings remain an important administrative and dissemination tool especially in the health sector where current knowledge, policies, and standards are positively impacted by the multisectoral and multidisciplinary sharing of best practices and methods among health professionals, educators, and public health practitioners. Careful consideration of details, such as scheduling, budgeting, advertising, including the accessibility of the venue and comfort of the attendees, are undoubtedly critical in the success of any meeting. However, such attention should not distract meeting planners from the big picture. Conferences are meant to bring the right people together. These gatherings promote not only the discussion and dissemination of ideas and results, but also serve as an important venue for sowing and even forging collaborative partnerships that link not only people and organizations, but also coordinate a more effective allocation of resources, delivery of care, as well as the sharing of expertise. The creative energy generated by such interactions yield not only innovative ideas but also help produce new generations of critical thinkers and decision makers. As such, the lasting impact of a conference is critically determined not only on how well each and every detail is laid out, but also on how sufficiently and accurately topics and speakers are selected to address pressing health problems, issues, and concerns.

\section{References}

Centers for Disease Control and Prevention (CDC). (1997). Securing approval for sponsorship of conferences. Manual guide - General administration CDC-1. Retrieved September 28, 2006, from http://www.cdc.gov/od/foia/policies/securing.pdf

Gilgen, R. (2006). Conference planning guidelines. Retrieved September 15, 2006, from http://iallt.org/confplan.html 
Goldman, K., \& Schmalz, K. (2005). Health education tools of the trade: Tools for tasks that didn't come with the job description. Washington, DC: Sage Publications.

US Department of Justice. (2004). Conference planning guide. Retrieved September 28, 2006, from http://www.ojp.usdoj.gov/ovc/publications/infores/res/confguid/welcome.html

Author Information

Carl Hanson, Ph.D., CHES*

229-D Richards Building

Department of Health Science

Brigham Young University

Provo, UT 84602

Ph.: 801-422-9103

Fax.: 801-422-0273

E-Mail: Carl_Hanson@byu.edu

M. Lelinneth

L. B. Novilla, MD, MPH

Michael Barnes, PhD, CHES

Department of Health Science

Brigham Young University

* corresponding author 